\title{
O bibliotecário e a administração burocrática na escola: olhares sobre o Projeto Político-Pedagógico e a atuação profissional
}

\author{
Everton da Silva Camillo \\ Mestrando; Universidade Estadual Paulista, Marília, SP, Brasil \\ evertonscamillo@outlook.com \\ Claudio Marcondes de Castro Filho \\ Doutor; Universidade de São Paulo, Ribeirão Preto, SP, Brasil \\ claudiomarcondes@ ffclrp.usp.br
}

\begin{abstract}
Resumo: Tem-se como pressuposto para esta pesquisa que bibliotecários escolares desenvolvem uma atuação meramente técnica em instituições organizacionais escolares, possivelmente corroborada pela adesão do modelo burocrático de administração nas escolas. Esse viés, contudo, colide com o reconhecimento da ambivalência técnico-intelectual do profissional de biblioteconomia, dadas as suas várias facetas e competências profissionais fundamentais ao cenário escolar do século XXI. Nesse sentido, objetivou-se apresentar a atuação profissional de bibliotecários escolares e as suas experiências com o Projeto Político-Pedagógico das escolas onde atuam, levando-se em conta o contexto da administração burocrática da escola. Metodologicamente, foi realizado um estudo exploratório, quantitativo e descritivo. Os dados foram coletados em quatro grupos temáticos da rede social Facebook a partir da aplicação de um questionário virtual do Google no mês de junho de 2018. Como resultado, foi obtido que: (1) há visão organizacional estreita por parte do grupo gestor de escolas, pois cria-se a impressão de que esse mesmo grupo inviabiliza a possibilidade de trabalho horizontalizado e concretamente interdisciplinar na escola e (2) há centralidade e burocracia institucionais que interferem no alcance e na possibilidade de contribuição dos demais profissionais da escola para a construção e/ou reformulação do Projeto Político-Pedagógico, ocasião em que o bibliotecário escolar se insere.
\end{abstract}

Palavras-chave: Biblioteca escolar. Projeto Político-Pedagógico. Pedagogia burocrática. Atuação profissional. Bibliotecário escolar.

\section{Introdução}

Quando pensamos o papel do bibliotecário na escola questionamos algumas das facetas em que esse profissional, nesse cenário, pode estar imerso. Isso é levado em conta, pois se tem como pressuposto para esta pesquisa que bibliotecários 
escolares desenvolvem uma atuação meramente técnica em instituições organizacionais escolares, possivelmente aderentes ao modelo burocrático de administração. Esse viés colide com o reconhecimento da ambivalência técnicointelectual do profissional de biblioteconomia, dadas as várias facetas e competências profissionais latentes desse profissional que são fundamentais ao cenário escolar do século XXI.

Nesse sentido, apresentamos como objetivo desta pesquisa a atuação profissional de bibliotecários escolares e suas experiências com o Projeto Político-Pedagógico (PPP) das escolas onde atuam, levando em conta o contexto da administração burocrática da escola.

Sobre o PPP, Gadotti (2001, p. 3) compreende que esse documento carrega "[...] sonhos, utopias que ele traduz tanto em relação à escola quanto em relação à sociedade que se quer construir.”, ao passo que, na mesma direção, Azevedo e Andrade (2012, p. 211) compreendem que a sua "[...] elaboração [...] implica na própria construção da identidade escolar.". Desse modo, o PPP é um instrumento de autonomia da instituição escolar. Também, é um documento que não é estático e que tem intencionalidade, além de perspectivas políticas, de permanência, reflexão e coletividade. Ele é um documento dotado de ideologia institucional e longe de ser meramente burocrático, pois norteia indagações institucionais do tipo: a) que cidadão formar?; b) que sociedade desejo construir?; c) o que entendo por ensino?; d) o que entendo por aprendizagem?; e) o que entendo como educação? e f) quais respostas esta escola está dando à sociedade? Por isso, ele é "[...] um projeto que implica, acima de tudo, um certo referencial teórico-filosófico e político. Ele não fica, contudo, no referencial. Ele implica em estratégias e propostas práticas de ação.” (GADOTTI, 2001, p. 3).

Como metodologia para a execução deste estudo, foi realizada uma pesquisa exploratória de natureza quantitativa com coleta de dados realizada em quatro grupos temáticos sobre biblioteconomia na rede social Facebook. Nesses grupos, foram publicados questionários virtuais dedicados a bibliotecários escolares. Esses questionários versaram sobre o contato, conhecimento e participação do bibliotecário escolar na elaboração do PPP da escola. Também abordaram questões sobre a percepção da equipe gestora das instituições 
escolares onde atuam, ao menos no que tange ao seu fazer biblioteconômico escolar.

\section{0 papel do bibliotecário na escola}

A biblioteca escolar enquanto equipamento informacional e cultural trabalha com as perspectivas da informação, do conhecimento e da cultura. Ela também é considerada um espaço de aprendizagem por excelência, onde ocorre a confluência dos saberes.

Para a IFLA/UNESCO (2000), a biblioteca escolar propicia informação e ideias fundamentais para seu funcionamento de forma exitosa na atual sociedade, com o foco na informação e no conhecimento. Esforços que, depreendidos da biblioteca escolar para a apropriação da informação e do conhecimento, possibilitam aos estudantes a aprendizagem ao longo da vida, a fim de prepará-los para viver como cidadãos emancipados, autônomos e responsáveis na sociedade civil organizada. Contudo, entende-se que para isso todo o processo de evolução cognitiva dos alunos no âmbito escolar não ocorre sem a mediação de profissionais capazes de viabilizar a informação e o conhecimento como molas propulsoras para a formação cidadã. Assim, é na biblioteca escolar que, além de serem valorizados o processo e o resultado das práticas de imersão informacional e cultural, o bibliotecário é visto como um colaborador para a mudança do universo social da escola. A IFLA/UNESCO (2000, não paginado) inferem que ele é um profissional capaz de assumir o posicionamento de liderança na escola: "O bibliotecário escolar é o membro profissionalmente qualificado, responsável pelo planejamento e gestão da biblioteca escolar.". Suas habilidades e competências profissionais devem atender, em primeira instância, aos anseios de toda uma comunidade escolar.

Como os serviços prestados pela biblioteca escolar dependem de recursos humanos qualificados e capacitados, o bibliotecário escolar também protagoniza a construção da prática educacional com os demais profissionais da educação na escola (MARTINS; KARPINSKI, 2018; IFLA, 2015), por isso entendemos que ele "Deve ser apoiado tanto quanto possível por equipe 
Everton da Silva Camillo e Claudio Marcondes de Castro Filho

adequada, [pois] trabalha em conjunto com todos os membros da comunidade escolar [...]", como imputa a IFLA/UNESCO (2000, não paginado).

É extremamente importante para o bibliotecário o fato de ser aceito como um membro igual aos outros profissionais e ser convocado para participar do trabalho conjunto e de todas as reuniões da escola, na qualidade de diretor do departamento bibliotecário. (IFLA/UNESCO, 2005, p. 12).

"Em cooperação com a direção da escola, com os administradores em geral e com o professorado, o bibliotecário deve estar envolvido no planejamento e na implementação dos programas escolares." (IFLA/UNESCO, 2005, p. 12). Logo, é papel desse profissional atuar nas várias frentes demandadas pelo ambiente escolar em detrimento da causa da educação, e isso envolve, portanto, o estabelecimento de um trabalho de perspectiva transversal, que conta com o apoio de outros profissionais no âmbito escolar.

Consideramos a atuação do bibliotecário junto à escola uma possibilidade de aplicação de uma metodologia dialógica, isso porque esta considera a problematização, a contextualização e a ação dos indivíduos a partir do trabalho coletivo, pois, em seus meandros, nascida e trabalhada no plano estratégico institucional, plasma-se em toda abordagem educativa e ambiência escolar, tendo em vista que o conhecimento não é apenas mediado, mas apreendido individualmente por meio das relações socialmente estabelecidas; perspectiva freireana de uma pedagogia para a libertação. O seu oposto é aquilo que Freire (1997) já chamava de 'educação bancária', que, opostamente ao pensamento libertador da educação, é aquela em que o professor "deposita" no aluno o conhecimento. "A concepção bancária de educação nega o diálogo, à medida que na prática pedagógica prevalecem poucas palavras [...]" (BRIGHENTE; MESQUIDA, 2016, p. 161).

Se a evolução cognitiva dos alunos no âmbito escolar ocorre também por meio da ação mediadora de profissionais imbuídos na viabilização da informação e do conhecimento, a presença da pedagogia burocrática nesse cenário culminará, portanto, em implicações de interferência em toda a cadeia da mediação da informação, pois, se não há dialogismo, supõe-se haver hierarquização e centralização nas relações, pontos que, à ótica da verticalidade, 
cerceiam a multiversalidade, propagando o contrário dela - a universalidade. E isso incidirá, portanto, no individualismo e, como consequência, na inibição do desenvolvimento da autonomia do sujeito, que pode levar à inviabilização do alcance da sua condição de sujeito emancipado (AZEVEDO; ANDRADE, 2007; AZEVEDO; ANDRADE, 2011; FORMOSINHO; ARAÚJO, 2007).

Nessa direção, Souza (2017) propõe que a relação que toma forma na atuação conjunta entre educadores e bibliotecários visa fortalecer a biblioteca escolar como equipamento informacional e cultural e a permite, como consequência, ser campo para o estudo de novas possibilidades de trabalho na educação. É nesse sentido que o bibliotecário deve contribuir com a proposta pedagógica da escola, a fim de desenvolver atividades variadas como possibilidade de ampliação da ação pedagógica. Também é nessa vertente que a atuação desse profissional mostra-se interdisciplinar, pois demonstra a importância do trabalho coletivo com os demais profissionais da escola para o alcance da educação. Castro Filho destaca que um dos atributos do bibliotecário é a "[...] cultura de captura e compartilhamento do conhecimento; trabalho em equipe incluindo profissionais de outras áreas [...]; e adoção de práticas de gestão do conhecimento e de um novo estilo de gestão da biblioteca." (CASTRO FILHO, 2016, p. 254). Desse modo, o papel do bibliotecário na escola não deve ser visto intrinsecamente relacionado com os aspectos unicamente endógenos à biblioteca, mas relacionado, inclusive, com os fatores exógenos a esta. Importa essa consideração, pois a concepção hierárquico-hegemônica escolar existente em inúmeras instituições escolares confere ao bibliotecário escolar funções meramente técnicas, como se este não pudesse analisar, contextualizar, problematizar e inferir sobre decisões a serem tomadas noutros planos organizacionais. Para a IFLA/UNESCO (2005, p. 14), o bibliotecário escolar deve "[...] participar do planejamento de atividades relacionadas à implementação do programa escolar [...]”.

É inegável, portanto, que há uma vertente de trabalho técnico nas competências profissionais do bibliotecário escolar. Também há outra que chama a atenção para a sua intelectualidade profissional, sendo que a soma da primeira com a segunda o torna um profissional ambivalente, isto é, técnicointelectual. 
Everton da Silva Camillo e Claudio Marcondes de Castro Filho

O não reconhecimento dessa ambivalência pela escola durante a atuação do bibliotecário incide na supressão das suas várias facetas, habilidades e competências profissionais para o contexto escolar especificamente, e isso pode levá-lo, enquanto profissional, à diminuição do seu engajamento à reflexão para com a unidade onde atua, levando-o a banalizar a sua intrínseca potencialidade de transformação no/do cenário escolar como um todo, reação pouco motivada por si próprio, mas impulsionada por visões míopes da escola impregnadas em gestões escolares que se embasam numa pedagogia inflada por vieses burocráticos.

\section{A administração burocrática na escola}

Os montes de papel, carimbos, documentos, logística documental para assinaturas e a pressa para a finalização das atividades no cenário de uma empresa contemporânea são alguns dos símbolos que muitos recorrem à representação do modelo burocrático no campo da Administração na atualidade; esse que é um modelo que surge no mundo em função da necessidade de métodos teóricos que possibilitassem uma abordagem global e integrada dos problemas organizacionais à medida que as organizações cresciam e necessitavam de modelos mais definidos que se aplicassem a grandes estruturas. Com isso, as obras de Max Weber, que rapidamente foram aplicadas de forma prática, proporcionaram as bases para o delineamento da Teoria da Burocracia (CRUZ, 2006).

Para Viana (2015, p. 268) “A burocracia possui o poder de decisão.”, além de que ela "[...] existe para efetivar o controle social." (VIANA, 2015, p. 269). Como forma de organização social, a burocracia é percebida ante as relações entre dirigentes e dirigidos. Como supõe o simbolismo a seu respeito, a burocracia é instituída, legitimada e estruturada por meio de normas escritas, tal como regulamentos, regimentos e leis. O seu funcionamento também determina o funcionamento hierárquico, o processo decisório, os meios formais de admissão, as funções do quadro de dirigentes e demais indivíduos imersos no modelo burocrático. Já a burocracia como classe social só pode ser compreendida quando posta no interior da divisão social do trabalho da 
Everton da Silva Camillo e Claudio Marcondes de Castro Filho

sociedade capitalista. Essa divisão social toma forma à medida que as classes sociais são constituídas pelas relações de produção dominantes, constituindo atividades fixas para um determinado conjunto de indivíduos. Consequentemente, isso incide na geração de um modo de vida e interesses comuns, além do destaque da luta comum contras outras classes sociais (VIANA, 2015).

Weber (1991) relata que a dominação pela burocracia significa:

[...] a dominação da impessoalidade formalista: sine ira et studio, sem ódio e paixão, e, portanto, sem "amor" e "entusiasmo", sob a pressão de simples conceitos de dever, sem considerações pessoais, de modo formalmente igual para "cada qual", isto é, cada qual dos interessados que efetivamente se encontram em situação igual - é assim que o funcionário ideal exerce seu cargo. (WEBER, 1991, p. 147).

Com isso o pensamento racional é importado para dentro do âmbito administrativo e das organizações, pois, de acordo com o ideário weberiano, é a racionalidade que deve orientar as ações dos que exercem os cargos nas empresas e, por isso, a impessoalidade formalista se torna um imperativo para a manutenção da organização. É por isso que a organização burocrática chega ao contexto da escola brasileira, pois há uma importação desse pensamento para dentro da vertente escolar.

A partir do ano de 1930, no contexto do Estado Novo, a administração escolar é marcada pela imposição de funções próximas daquelas instituídas nas empresas. Para Tavares, Azevedo e Morais (2014, p. 159), essa forma de administrar interveio na "[...] organização da educação [que] passa a ser baseada na perspectiva burocrática em que a racionalidade penetra na escola e influencia o processo pedagógico.”. Isso conduz a escola a primar pela rigidez organizacional baseada na normatização de ações e a faz abrir-se à compartimentalização do saber e especialização das funções, contexto de onde surge a pedagogia pragmática que oferece a técnica como solução para resolver problemas educacionais.

Secchi (2009) considera que o modelo burocrático weberiano foi um modelo organizacional amplamente disseminado nas administrações públicas 
Everton da Silva Camillo e Claudio Marcondes de Castro Filho

durante o século XX em todo o mundo, e, desde o século XVI, sua utilização houvera sido bastante difundida tanto nas administrações públicas quanto nas organizações religiosas e militares, especialmente na Europa. No entanto, no século $\mathrm{XX}$, esse modelo vem à tona em organizações públicas, privadas e do terceiro setor, embora haja muitas críticas sobre a sua aplicação. Mesmo que autores salientem a eficácia desse modelo de administração, alguns dos seus efeitos negativos, chamados de disfunções burocráticas, como bem elenca Secchi (2009), podem ser percebidos: a) impacto da prescrição estrita de tarefas sobre a motivação dos empregados; b) resistência às mudanças; c) desvirtuamento de objetivos provocados pela obediência acrítica das normas. Com isso, mesmo que haja a busca pela eficiência dos processos dentro das instituições organizacionais, o modelo burocrático nesses ambientes tende a cercear a oportunidade de gênese de motivação, podendo gerar, inclusive, resistência às mudanças, já que o que passa a entrar em voga é o impacto da prescrição de tarefas para o alcance da eficiência organizacional por meio da obediência acrítica das normas pelos sujeitos. No contexto da escola, ao que afirmam Tavares, Azevedo e Morais (2014, p. 160), não é diferente, dado que “[...] o dirigente educacional na figura do diretor impõe as normas e regulamentos que devem orientar o processo de organização da escola e cabe ao professor e demais executá-los.”.

Nessa seara, a escola é permeada por forte senso de hierarquia, o que a caracteriza como uma organização fortemente burocrática. Isso quer dizer que a busca pela eficiência no âmbito escolar é exercida, sobremaneira, por meio da racionalidade e impessoalidade do modelo de administração instituído em/para a massa. Entretanto, não é difícil percebermos que a instituição desse modelo que direta e indiretamente perpassa a ação pedagógica nas escolas não consegue se aderir às demandas do século XXI, ao menos no que tange ao campo da educação, levando-se em conta um contexto secular que tem novas concepções de ensinar e aprender e que requer da organização escolar um novo modo de conceber a sua forma de administrar e perceber seus recursos humanos. 


\section{Metodologia}

Everton da Silva Camillo e Claudio Marcondes de Castro Filho

Buscar o entendimento da atuação profissional de bibliotecários escolares e suas experiências com o Projeto Político-Pedagógico das escolas onde atuam, no contexto de uma administração burocrática da escola, permitiu-nos caracterizar esta pesquisa como exploratória. Gil (1999, p. 27), ao que já afirmara, considera que "Este tipo de pesquisa é realizado especialmente quando o tema escolhido é pouco explorado [...]". É um estudo descritivo e quantitativo: descritivo, pois apresenta dados coletados a partir da resposta de 80 questionários respondidos virtualmente por bibliotecários escolares, entre homens e mulheres, de vários Estados brasileiros; e quantitativo, pois, por meio das realidades compreendidas durante a aplicação do questionário estruturado, informações sobre a atuação e percepção de âmbito profissional surgiram e tornaram-se parte do insumo da discussão.

Para o desmembrar da pesquisa, partimos das seguintes indagações: (1) quais são as implicações decorrentes de um pensamento burocrático no âmbito escolar? e (2) em que esse posicionamento burocrático, incutido nas instituições escolares, implica no desempenho de bibliotecários na escola? Desse modo, a coleta de dados foi realizada a partir da aplicação de um questionário virtual estruturado em quatro grupos da rede social Facebook, a saber: (1) Bibliotecários do Brasil (14.677 mil membros); (2) Biblioteconomia Encontros (2.771 mil membros); (3) Biblioteconomia Brasil (1.477 mil membros) e (4) Bibliotecários Escolares do Brasil (776 membros). Os critérios escolhidos para selecionar os grupos foram: (1) número de membros acima de 500 e (2) membros de ambos os sexos e gerações diferentes de bibliotecários, variando, consequentemente, em anos de formação e grau de experiência profissional.

O questionário aplicado buscava por respostas a perguntas enquadradas nas seguintes temáticas:

a) contato dos bibliotecários respondentes com o PPP da escola onde atuam;

b) a participação desses bibliotecários no planejamento do PPP da escola onde atuam; 
Everton da Silva Camillo e Claudio Marcondes de Castro Filho

c) o sentimento desses bibliotecário em relação ao reconhecimento do desempenho do seu trabalho numa perspectiva transformadora para a comunidade escolar;

d) e o sentimento desses bibliotecários em relação à problematização e compreensão do seu trabalho pelo corpo gestor da escola.

A coleta dos dados na rede Facebook foi feita durante as últimas três semanas do mês de junho de 2018. Para tanto, foi realizada uma postagem do link de acesso ao questionário de perguntas fechadas, previamente elaborado com os formulários do Google, nos quatro grupos com temática de biblioteconomia. A publicação continha uma breve explicação - o objetivo deste trabalho - sobre a intencionalidade da aplicação do questionário, o que permitiu alcançar o interesse e a livre participação de algumas pessoas que integram os grupos. As perguntas que compuseram o questionário foram:

a) em qual Estado brasileiro você atua como bibliotecário?;

b) você já teve algum tipo de contato com o PPP da escola onde atua?;

c) como bibliotecário, você já participou da elaboração do PPP da sua escola?;

d) você sente que a comunidade escolar reconhece seu trabalho como potencial para a transformação da própria realidade escolar?;

e) e você sente que na escola onde atua o grupo gestor não problematiza e compreende a sua prática profissional?

Portanto, após a obtenção das respostas, os questionários foram analisados estatisticamente e com considerações oriundas não apenas da realidade que os descrevem, mas com inferências teóricas que fundamentam essas realidades. 
Everton da Silva Camillo e Claudio Marcondes de Castro Filho

\section{Resultados e discussões}

Com a aplicação do questionário nos quatro grupos temáticos sobre biblioteconomia na rede social Facebook, obtivemos um total de 80 respostas: 76 do sexo feminino (95\%) e quatro do sexo masculino (5\%). Sabe-se que a maior parte dos respondentes do questionário é do Estado de São Paulo (22) (Gráfico 1). A região sudeste, segundo a página eletrônica do Conselho Regional de Biblioteconomia (2018), é a que mais possui cursos de biblioteconomia em universidades: 17 cursos no total, sendo sete em universidades federais/estaduais e dez em particulares. Nesse caso, nove dos 17 cursos de biblioteconomia na região sudeste do Brasil situam-se no Estado de São Paulo, dado que justifica o maior número de bibliotecários que responderam ao questionário serem dessa região. Depois de São Paulo, vem o Rio Grande do Sul (14). Rio de Janeiro e Minas Gerais empatados (8) e Bahia e Santa Catarina também com valores iguais (6). Distrito Federal (3) e Espírito Santo (2) diferem dos demais Estados elencados no gráfico, pois somam apenas um respondente cada.

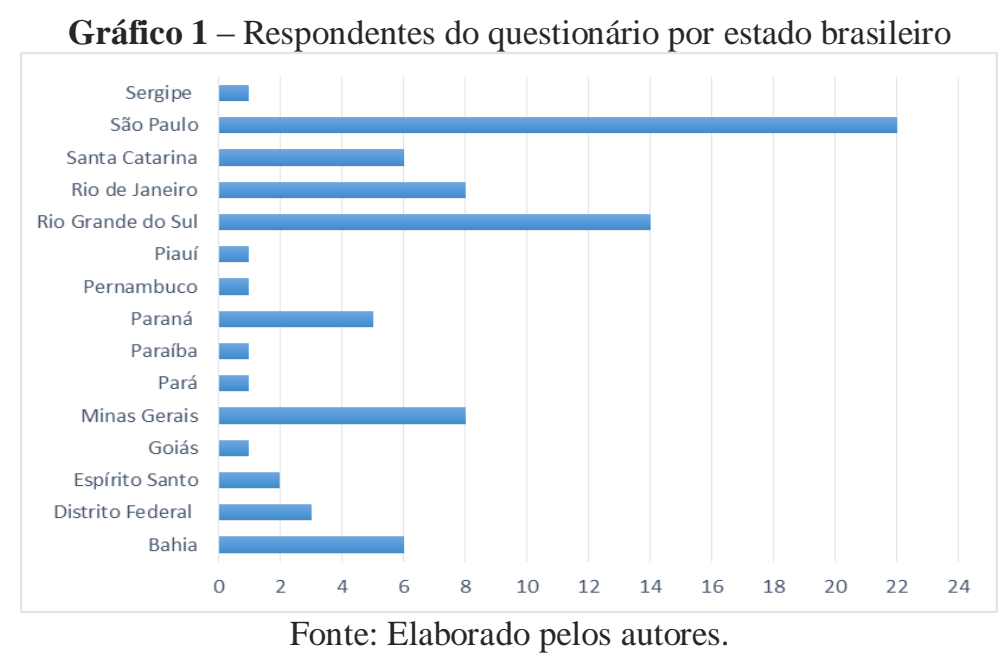

Os profissionais desses 15 estados brasileiros elencados no gráfico 1 são profissionais que atuam, em sua maioria, de um a quatro anos na mesma escola $(43,8 \%)$, valor que corresponde a 35 respondentes. Seguindo, tem-se que 19 respondentes trabalham há menos de um ano na atual instituição $(23,8 \%)$ e outros 14 atuam de quatro a oito anos no mesmo local (17,5\%). Os demais 
Everton da Silva Camillo e Claudio Marcondes de Castro Filho

questionados, que juntos somam 12 respondentes, têm a menor percentagem (15\%). Esse índice se refere àqueles que atuam há mais de oito anos na mesma instituição escolar.

Quando perguntamos sobre o conhecimento do que é um PPP, 75 $(93,8 \%)$ dos bibliotecários respondentes afirmaram saber do que trata esse documento, embora cinco $(6,3 \%)$ afirmaram não ter nenhum conhecimento sobre. Contudo, quando perguntados sobre o contato com esse documento nas escolas onde atuam, aproximadamente metade dos respondentes (38 pessoas, ou 47,5\% destes) declararam nunca ter tido nenhuma forma de contato (manuseio, leitura) (Gráfico 2).

Gráfico 2 - Contato com o PPP da escola onde atuam

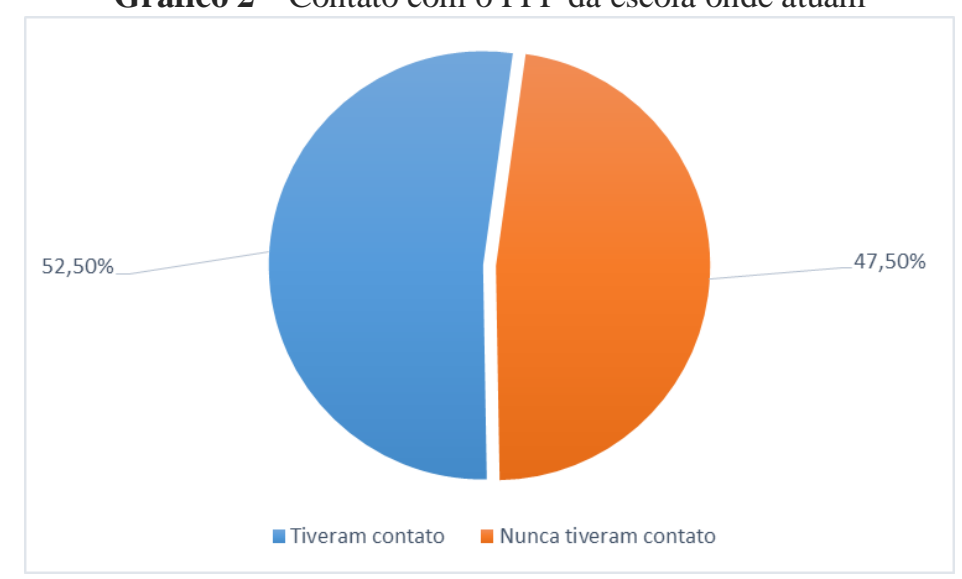

Fonte: Elaborado pelos autores.

Frente a isso, o bibliotecário escolar, à medida que trabalha na ordem de oferta do aprendizado, ensino, pesquisa e divulgação do pensamento, arte e saber para a promoção da educação na escola, deve não só compreender, mas propriamente conhecer o PPP local, concebendo-o como um documento perpassado também pelo seu contributo técnico-intelectual e experiência profissional.

Para Padilha (2001, p. 73), “[...] pensar o planejamento educacional e, em particular, o planejamento visando ao projeto político-pedagógico da escola é, essencialmente, exercitar nossa capacidade de tomar decisões coletivamente." .O autor sustenta que a construção do PPP de uma escola nasce da mistura de princípios, estratégias concretas e muito trabalho coletivo. Prontamente, fica evidenciado que “[...] a decisão e a iniciativa coletiva conseguem resolver 
Everton da Silva Camillo e Claudio Marcondes de Castro Filho

problemas concretos da prática educativa que, num primeiro momento, pareciam impossíveis de ser superados.” (PADILHA, 2001, p. 74).

Assim, é de responsabilidade da equipe gestora da escola romper com a miopia institucional que incita a segregação e hegemonização, no âmbito escolar, do ato de educar. Também é direito do bibliotecário conhecer e participar da elaboração do PPP enquanto ferramenta ideológico-norteadora. Azevedo e Andrade (2012, p. 205) declaram: o PPP “[...] é o principal ponto de referência para a construção da identidade escolar e dos profissionais que nela atuam [...]". Contrariamente a essa fundamentação, os dados dos questionários mostram que a grande maioria dos participantes da pesquisa, 77,5\% deles, ou 62 profissionais, relataram nunca ter participado do planejamento do PPP da escola onde atuam (Gráfico 3).

Gráfico 3 - Participação no planejamento do PPP da escola onde atuam

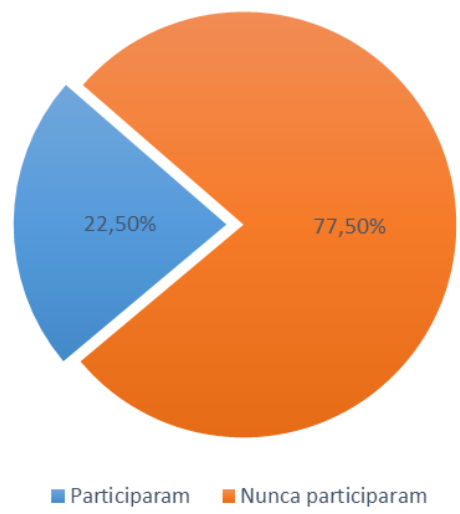

Fonte: Elaborado pelos autores.

Ao considerarmos o bibliotecário simbolicamente como engrenagem num sistema vivo como é o escolar, importa incluí-lo e desenvolvê-lo, dar-lhe voz. Entretanto, a contramão desse anseio é "a concepção burocrática [que] [...] 'tolera' [apenas] ao professor a inovação pedagógica [...]" (FORMOSINHO; ARAÚJO, 2007, p. 319), deixando os demais profissionais da escola relegados a esse direito. Esse tipo de postura por parte da gestão escolar, como entendimento mediante o referencial teórico e análise dos questionários, leva bibliotecários a se sentirem desencorajados ao desenvolvimento de ações criativas e inventivas na escola. É visto que 53,8\% dos bibliotecários relataram sentir-se encorajados, ao passo que $46,3 \%$ desses, isto é, quase metade deles, 
Everton da Silva Camillo e Claudio Marcondes de Castro Filho

sentem-se desencorajados. Contudo, quando perguntados sobre sentirem que a comunidade escolar reconhece seu trabalho como um com potencial para a transformação social da escola e sobre sentirem que, na escola onde atuam, o grupo gestor problematiza e compreende suas práticas profissionais, obteve-se altos índices percentuais em respostas negativas, como visto nos gráficos 4 e 5, a seguir:

Gráfico 4 - Sentimento de reconhecimento do trabalho do bibliotecário como transformador à escola

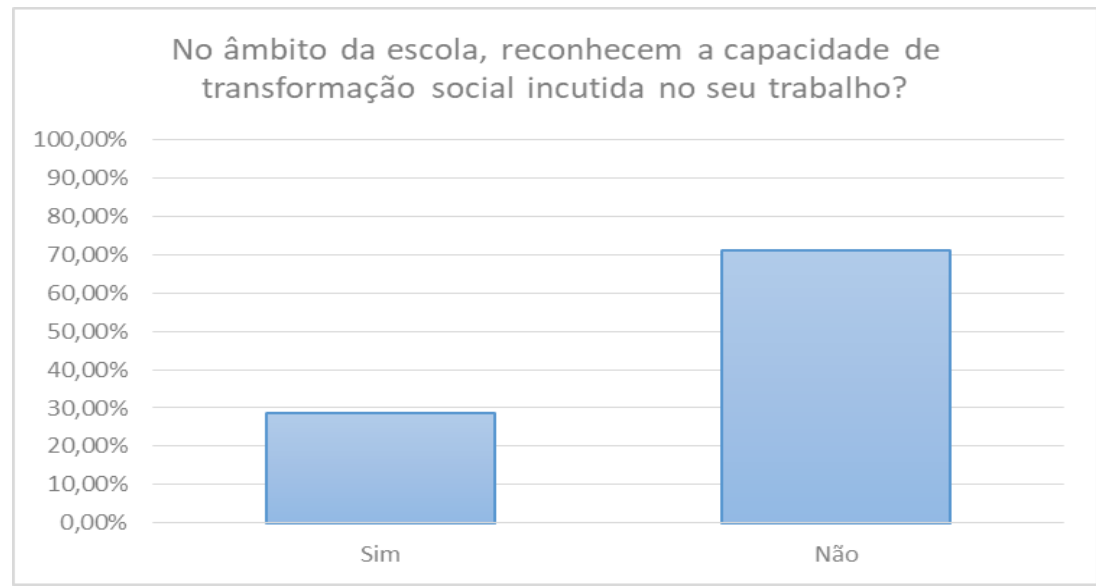

Fonte: Elaborado pelos autores.

Gráfico 5 - Sentimento de problematização e compreensão da atuação do bibliotecário na escola

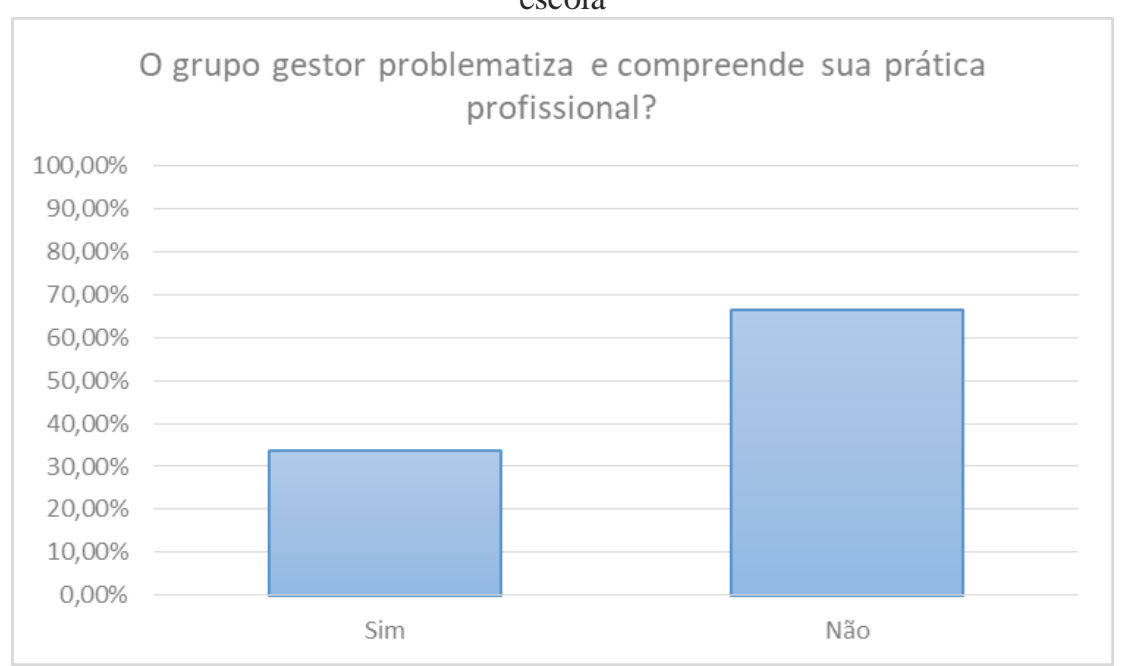

Fonte: Elaborado pelos autores.

Fica evidente, portanto, que grande parte dos bibliotecários atua em instituições que privilegiam a abordagem hierárquico-centralizadora, na qual o corpo docente, supostamente, pode ter mais crédito, visibilidade, abertura ao 
Everton da Silva Camillo e Claudio Marcondes de Castro Filho

diálogo e oportunidade de trabalhos transversais do que os profissionais de biblioteconomia. Com isso, cria-se um discurso de que, aparentemente, é papel do bibliotecário cuidar única e exclusivamente da sua biblioteca, pois, preso a uma lógica burocrática da instituição escolar, ele parece exercer e reforçar um de seus estereótipos mais vivos no imaginário social, aquele em que o posicionam frente a um trabalho de natureza arcaica, isto é, a realização da custódia de registros físicos de informação em bibliotecas.

\section{Considerações finais}

Mais do que assumir papeis meramente técnicos em instituições organizacionais, o bibliotecário deve ser visto como um profissional em sua forma lato, isto é, detentor também de uma perspectiva intelectual no seu modus operandi. É relevante ter isso em mente quando se percebe que é comum que a biblioteca seja vista como a máxima do trabalho do bibliotecário na escola, um profissional que se torna fragmentado devido à desvinculação da sua dimensão intelectual daquela de ordem técnica.

Mediante a análise dos gráficos, parece-nos que ainda há centralidade e burocracia institucionais interferindo no alcance e na possibilidade de contribuição dos demais profissionais da escola para a construção e/ou reformulação do PPP. Concluiu-se também que grupos gestores, mediante a descrição dos dados, têm visão institucional e profissional estreitas, pois rompem com os elos por meio dos quais se poderia tecer uma grande teia dialógica entre colaboradores, quer sejam professores ou bibliotecários, dentre outros, perpassando, de modo natural, as lideranças da escola. Com isso, ficaria mais claro ver o desenvolver de ações munidas de caráter holístico, inclusivo, dialógico e organizativo nas gestões escolares. Contudo, fica evidente que a miopia vinculada a algumas das gestões escolares atuais, no que tange a essa concepção de atuação, propõe tanto à escola quanto aos seus profissionais que caminhem na contramão da perspectiva colaborativa. 
Everton da Silva Camillo e Claudio Marcondes de Castro Filho

\section{Financiamento}

Coordenação de Aperfeiçoamento de Pessoal de Nível Superior (CAPES).

\section{Referências}

AZEVEDO, M. A. R.; ANDRADE, M. F. R. O conhecimento em sala de aula: a organização do ensino numa perspectiva interdisciplinar. Educar, Curitiba, n. 30, p. 235-250, 2007.

AZEVEDO, M. A. R.; ANDRADE, M. F. R.. O papel da interdisciplinaridade e a formação do professor: aspectos histórico-filosóficos. Educação Unisinos, São Leopoldo, v. 15, n. 3, p. 206-2013, set./dez. 2011.

AZEVEDO, M. A. R.; ANDRADE, M. F. R.. Projeto político-pedagógico e o papel da equipe gestora: dilemas e possibilidades. Interacções, Lisboa, n. 21, p. 204-2018, 2012.

BRIGHENTE, M. F.; MESQUIDA, P. Paulo Freire: da denúncia da educação bancária ao anúncio de uma pedagogia libertadora. Pro-Posições, Campinas, v. 27, n. 1, p. 155-177, jan./abr. 2016.

CASTRO FILHO, C. M. As competências, os perfis e os aspectos sociais do bibliotecário na educação. RDBCI: Revista Digital de Biblioteconomia e Ciência da Informação, Campinas, v. 14, n. 2, p. 247-261, maio/ago. 2016.

CONSELHO REGIONAL DE BIBLIOTECONOMIA $6^{\mathrm{a}}$ REGIÃO. Carreira. Belo Horizonte. 2018.

CRUZ, J. A. W. A burocracia fora do senso comum. Perspectivas Contemporâneas, Campo Mourão, v. 1, n. 1, p. 1-10, jan./jul. 2006.

FREIRE, P. Pedagogia da autonomia: saberes necessários à prática educativa. São Paulo: Paz e Terra, 1997.

FORMOSINHO, J.; ARAÚJO, J. M. Anônimo do século XX: a construção da pedagogia burocrática. In: OLIVEIRA-FORMOSINHO, J.; KISHIMOTO, T. M.; PINAZZA, M. A. (org.). Pedagogia(s) da infância: diálogos com o passado: construindo o futuro. Porto Alegre: Artmed, 2007. p. 293-327.

GADOTTI, M. Dimensão política do projeto pedagógico da Escola. In: MINAS GERAIS. Projeto de capacitação de dirigentes - PROCAD. Projeto político e pedagógico da escola. Belo Horizonte: SEE-MG, 2001. (Guia de estudos; 3).

GIL, A. C. Métodos e técnicas de pesquisa social. 5. ed. São Paulo: Atlas, 1999.

IFLA - INTERNATIONAL FEDERATION LIBRARY ASSOCIATIONS AND INSTITUTIONS. IFLA School Library Guidelines. 2. ed. Haag: IFLA, 2015. 
IFLA - INTERNATIONAL FEDERATION LIBRARY ASSOCIATIONS AND INSTITUTIONS; UNESCO - ORGANIZAÇÃO DAS NAÇÕES UNIDAS PARA A EDUCAÇÃO, CIÊNCIA E A CULTURA. Manifesto IFLA/UNESCO para biblioteca escolar. São Paulo: IFLA, 2000.

IFLA - INTERNATIONAL FEDERATION LIBRARY ASSOCIATIONS AND INSTITUTIONS; UNESCO - ORGANIZAÇÃO DAS NAÇÕES UNIDAS PARA A EDUCAÇÃO, CIÊNCIA E A CULTURA. Diretrizes da IFLA/UNESCO para a biblioteca escolar. São Paulo: IFLA, 2005.

MARTINS, S.; KARPINSKI, C. Interdisciplinaridade e formação do bibliotecário para atuação em Bibliotecas Escolares. Informação \& Informação, Londrina, v. 23, n. 1, p. 424-449, jan./abr. 2018.

PADILHA, P. R. Planejamento dialógico e projeto político-pedagógico da escola. In: PADILHA, P. R. Planejamento dialógico: como construir o projeto político-pedagógico da escola. São Paulo: Cortez; Instituto Paulo Freire, 2001. p. 73-93.

SECCHI, L. Modelos organizacionais e reformas da administração pública. Revista de Administração Pública, Rio de Janeiro, v. 43, 2, p. 347-369, mar./abr. 2009.

SOUZA, A. C. P. Biblioteca escolar: refletindo sobre a importância da cooperação entre o bibliotecário e a equipe pedagógica da escola. Biblionline, João Pessoa, v. 13, n. especial, p. 27-30, 2017.

TAVARES, A. M. B. N.; AZEVEDO, M. A.; MORAIS, P. S. A administração burocrática e sua repercussão na gestão escolar. Holos, Natal, v. 30, v. 2, p. 154162, 2014.

VIANA, N. Burocracia: forma organizacional e classe social. Marxismo e Autogestão, Goiânia, v. 2, n. 3, p. 265-285, jan./jun. 2015.

WEBER, M. Economia e sociedade: fundamentos da sociologia compreensiva. Brasília: Editora UnB, 1991.

\title{
The librarian and the bureaucratic administration at school: an approach of the Political-Pedagogical Project and the professional performance
}

\begin{abstract}
It is assumed as a presupposition for this study that school librarians develop a merely technical performance in schools possibly corroborated by the adhesion of the bureaucratic model of administration. This bias, however, conflicts with the acknowledgment of the technical-intellectual ambivalence of the library professional, given its various facets and professional skills that are fundamental to the school scene of the twenty-first century. In this sense, this
\end{abstract}


study aimed to present the professional performance of school librarians and their experiences with the Political-Pedagogical Project of the schools where they work, considering the context of the school's bureaucratic administration. Methodologically, it was carried out a study of exploratory, quantitative and descriptive approaches. We collected the data in four Facebook thematic groups from the application of a virtual questionnaire in the month of June 2018. As a result, we obtained that: (1) there is a narrow organizational vision on the part of the group of schools, because it creates the impression that this same group makes the possibility of horizontally and concretely interdisciplinary work impossible in the school and (2) there are institutional centrality and bureaucracy that interfere in the reach and possibility of contribution of the other professionals of the school for the construction and/or reformulation of the Political-Pedagogical Project, when the school librarian joins.

Keywords: School library. Political Pedagogical Project. Bureaucratic pedagogy. Professional performance. School librarian.

Recebido: $10 / 07 / 2018$

Aceito: 03/12/2018 